\title{
DISCURSOS DOMINANTES DE LETRAMENTO EM QUESTÕES DE VESTIBULAR
}

\author{
Gabriel Valdez Foscaches* \\ Guilherme Veiga Rios* \\ Universidade de Brasília \\ Instituto de Letras \\ Dep. de Linguística, Português e Línguas Clássicas \\ Brasília, DF, Brasil
}

\begin{abstract}
Resumo: Nas sociedades contemporâneas, os indivíduos são constantemente avaliados pelo domínio que possuem da escrita. No caso das provas de vestibular, a escrita é simultaneamente meio e objeto de avaliação. Ao considerarmos a escrita como objeto de avaliação em provas de vestibular, trazemos para o debate as discussões desenvolvidas na área dos Novos Estudos de Letramento e da Análise de Discurso Crítica. Com base nestas duas teorias, fornecemos algumas respostas para as seguintes questões: a) que valor se atribui à escrita no vestibular; b) o que se entende por domínio da escrita; e c) quais são os discursos de letramento adotados nos exames? Encontramos, ao final, que os discursos de letramento subjacentes às questões analisadas reforçam visões naturalizadas sobre a escrita e a norma-padrão, afetando as identidades dos indivíduos em relação ao uso que fazem de variedades linguísticas nessa modalidade.
\end{abstract}

Palavras-chave: Análise de Discurso Crítica. Letramento. Vestibular.

10 VALOR DA ESCRITA NA ATUALIDADE

É inegável o valor atribuído à escrita na contemporaneidade. Além de necessário para o exercício de certos direitos - como concorrer a cargos políticos ${ }^{1}-$, o domínio da escrita é um pré-requisito para o acesso ao ensino superior e a cargos públicos, espaços ocupados por indivíduos que passam por penosos processos de seleção - realizada por meio do gênero discursivo questão de prova. Apesar de haver vários tipos de questão de prova, discutiremos especificamente um deles: a questão de prova de vestibular.

O gênero questão de prova de vestibular não é acessível a todos. Para ter acesso a esse gênero, é necessário: a) dominar determinadas habilidades de leitura e escrita; b) ter passado por todo o processo de escolarização básica, no caso do avaliado; c) ter passado pelo processo de escolarização básica e, no mínimo, ter concluído o nível superior, no caso do avaliador.

\footnotetext{
* Mestre em Linguística pela Universidade de Brasília, DF. E-mail: gbvafo@gmail.com.

** Doutor em Linguística pela Lancaster University, Reino Unido. Pesquisador-tecnologista da Diretoria de Avaliação da Educação Básica/Instituto Nacional de Estudos e Pesquisas Educacionais Anísio Teixeira/Ministério da Educação. Pesquisador e Professor Colaborador do Programa de Pós-graduação em Linguística da UnB. E-mail: gveigarios@gmail.com.

${ }^{1}$ Conforme dispõe o art. 14, § $4^{\circ}$, da Constituição Federal, os analfabetos são inelegíveis. Há também discussões no congresso sobre o direito do analfabeto de votar. Atualmente, o alistamento eleitoral e o voto são facultativos para os analfabetos.
} 
A questão de prova de vestibular não surge na vida das pessoas apenas no fim do processo de escolarização; esse gênero discursivo exerce uma grande influência nos letramentos desenvolvidos em práticas escolares, principalmente no ensino médio, pois ele estabelece quais tipos de letramento são objeto de avaliação e, por conseguinte, estabelece quais tipos de letramento devem ser desenvolvidos na escola.

Durante todo o processo de escolarização, desenvolve-se não só a habilidade de escrever/ler, mas também ideologias ${ }^{2}$ sobre a escrita. Conforme mostra Rios (2013) em sua pesquisa sobre discursos de letramento, essas ideologias ajudam a criar o imaginário de que as pessoas letradas são intelectualmente superiores às pessoas não letradas ${ }^{3}$.

A visão de que as pessoas letradas são intelectualmente mais hábeis é reforçada pelos processos de avaliação, que - como mostram Shohamy (2014) e Soares (1991) são usados para exercer o controle do conhecimento e das hierarquias sociais. Nas questões de prova, o conhecimento é avaliado por meio da escrita, mas isso não significa que o conhecimento também seja "adquirido" somente por meio da escrita, como costumam pensar as pessoas que atrelam rigidamente o desenvolvimento do indivíduo à aquisição da escrita.

De um modo geral, as pessoas costumam acreditar que a aquisição da escrita produz efeitos automáticos sobre os indivíduos e sobre a sociedade, como o desenvolvimento de um raciocínio lógico superior e o desenvolvimento econômico ${ }^{4}$. Essa perspectiva é denominada por Street (1984) Modelo Autônomo de Letramento. Nesse modelo, acreditase que a linguagem escrita é superior à linguagem falada, e os indivíduos que dominam a escrita também são superiores aos que não a dominam. Embora tenha feito algum sucesso entre os anos 1960 e 1970, essa visão de que o domínio da escrita produz efeitos imediatos nas capacidades cognitivas das pessoas já foi questionada por numerosos estudos em âmbito internacional, e mesmo nacional, nas áreas da psicologia, história, etnografia e linguística, conforme se pode ver em Soares (2004).

Em oposição ao Modelo Autônomo, Street (1984) define o Modelo Ideológico de Letramento. Nesse último, as habilidades e conceitos que acompanham a aquisição do letramento não derivam automaticamente das qualidades inerentes à escrita. Antes essa representação mistificada da escrita é uma representação ideológica, que afeta nossa visão sobre as pessoas que possuem e as que não possuem o domínio da escrita.

\footnotetext{
2 Segundo Thompson (2002, p. 85), "estudar a ideologia é estudar as maneiras pelas quais o significado serve para estabelecer e sustentar as relações de dominação".

${ }^{3}$ Como exemplo desse imaginário, podemos citar a pesquisa de Norton e Kamal (2003), que levantou algumas representações sobre letramento no Paquistão. Destacamos a seguir algumas proposições que trazem o núcleo dessas representações: "O letramento desempenha um papel vital no progresso de um país"; "se não formos letrados não podemos fazer nenhum trabalho intelectual", pessoas letradas podem "tomar decisões melhores" (NORTON; KAMAL, 2003, p. 306).

${ }^{4}$ A respeito da correlação entre escrita e desenvolvimento socioeconômico, Lévi-Strauss (1957, p. 317) já apontava o quanto a humanidade havia se desenvolvido antes do aparecimento da escrita: "Uma das fases mais criadoras da história da humanidade se situa no neolítico: responsável pela agricultura, a domesticação dos animais e outras artes. Para chegar a isso, foi preciso que, durante milênios, pequenas coletividades humanas observassem, experimentassem e transmitissem o fruto de suas reflexões. Esse imenso empreendimento desenrolou-se com um rigor e uma continuidade atestados pelo seu êxito, enquanto a escrita ainda era desconhecida. Se esta última apareceu entre o $4 .^{\circ}$ e o $3 .^{\circ}$ milênios antes de nossa era, devese ver nela um resultado já longínquo (e sem dúvida indireto) da revolução neolítica".
} 
Segundo Street (2003, p. 77), "o letramento varia de um contexto para o outro, de uma cultura para a outra e da mesma maneira, então, variam os efeitos de diferentes letramentos em diferentes condições". Todavia, ainda que os efeitos do letramento variem de uma cultura para outra, parece que a escrita também produz uma consequência constante, qual seja: a hierarquização das pessoas em castas e classes, conforme observa Lévi-Strauss (1957, p. 318). De acordo com esse último, o aparecimento da escrita "parece favorecer a exploração dos homens antes de iluminá-los".

Contudo, ao trazer essas ponderações, não queremos reduzir a importância da escrita, mas relativizar os discursos dominantes sobre a escrita, ou melhor, os discursos dominantes sobre letramento. Então, para desenvolver a discussão, é importante partir de uma definição de letramento.

\section{LETRAMENTO E LETRAMENTOS}

Segundo Rios (2010, p. 78), o termo letramento pode ser usado para designar: a) um campo de estudos - "um espaço interdisciplinar entre a Educação, a Linguística, a Psicologia e as Ciências Humanas e Sociais em geral"; e b) um processo que ocorre na vida social. Portanto, podemos dizer que, ao analisarmos, por uma perspectiva científica, o processo que ocorre na vida social (definição b), estamos nos situando no campo de estudos do letramento (definição a).

Com base em Street (1984), consideramos que o letramento (definição b) diz respeito às práticas sociais que envolvem o uso da escrita; logo, que envolvem também a leitura. Desse modo, letramento não se confunde com a alfabetização, que se refere ao processo de aquisição do sistema alfabético, restrito geralmente ao ambiente escolar (KLEIMAN, 1995). Existem, portanto, variadas práticas sociais envolvendo letramentos que não se limitam às práticas escolares - basta pensar em nosso cotidiano para verificar os diversos contextos em que usamos a escrita de forma mais ou menos padronizada.

Desse modo, seria melhor falar em letramentos (no plural). Por esse prisma, o letramento escolar constitui apenas um dos tipos de letramento - um tipo, como sabemos, dominante. Embora sejam bastante variados, os letramentos não são igualmente valorizados, como expõe Barton (1994). Por essa razão, convém falar em letramentos dominantes.

Um letramento é dominante quando ele se origina de uma instituição dominante da sociedade - a burocracia do Estado, por exemplo. Quando um letramento é representado como superior aos outros, podemos falar em discursos dominantes de letramento.

\footnotetext{
Discursos dominantes do letramento referem-se tanto a usos dominantes da escrita (e, consequentemente, da leitura), tais como aqueles considerados de status superior na burocracia, na academia e no uso literário, como às suas representações ou construções discursivas. Frequentemente, são esses os marcos de referência quando as pessoas emitem opinião sobre o letramento num sentido geral. (RIOS, 2013, p. 3).
}

A visão não hierarquizadora dos letramentos que adotamos pode parecer contraintuitiva, pois aprendemos durante toda a vida que algumas práticas de escrita, 
algumas normas linguísticas, alguns gêneros textuais etc. são superiores aos outros. Inclusive, os exames, ao elegerem somente os letramentos dominantes, reforçam esse imaginário, isto é, reproduzem os discursos dominantes de letramento.

Uma vez que essas ideologias sobre os letramentos são criadas e reproduzidas por meio do discurso, acreditamos que a Análise de Discurso Crítica tem muito a contribuir para os Novos Estudos de Letramento (ver RIOS, 2010).

\section{ANÁLISE DE DISCURSO CRÍTICA E LETRAMENTO}

Os Novos Estudos do Letramento propiciam um grande diálogo com a Análise de Discurso Crítica (ADC), que também é uma teoria interdisciplinar - ou melhor, transdisciplinar. As duas disciplinas dividem um arcabouço teórico que permite uma grande integração científica, pois têm como pano de fundo teorias e métodos das ciências sociais. Ambas focam suas análises nas práticas sociais, que, segundo Chouliaraki e Fairclough (1999, p. 21), são "maneiras habituais, vinculadas a tempos e espaços particulares, em que as pessoas aplicam recursos (materiais ou simbólicos) para agirem no mundo". As práticas que envolvem um considerável uso de letramentos são um tipo específico de prática social, em que a escrita é utilizada. Assim, Barton e Hamilton (2000, p. 8), ao falar em práticas de letramento, tratam das "maneiras culturais de utilizar o letramento".

Por estudar eventos que envolvem textos escritos, o Letramento, na condição de disciplina acadêmica, necessita de uma teoria-método, como a que propomos com a $\mathrm{ADC}^{5}$, que lide com esses objetos de forma sistemática, pois, conforme Barton e Hamilton (2000, p. 9) pontuam: "Textos são uma parte crucial dos eventos de letramento e o estudo do letramento é em parte o estudo de textos e de como eles são produzidos e usados".

Tanto a ADC como os Novos Estudos de Letramento não restringem sua análise aos textos, mas os localizam dentro de práticas sociais. Um dos pontos mais importantes da prática social é que ela articula o elemento discursivo (linguagem) com elementos sociais não discursivos. Além do discurso, podemos dizer, com base em Fairclough (2003), que a prática social é constituída por uma articulação de elementos como: ação e interação, relações sociais, pessoas (com crenças, atitudes, histórias etc.) e mundo material.

Outra diferenciação importante, tanto para os Novos Estudos do Letramento como para a ADC, é entre práticas de letramento e eventos de letramento. Se as práticas de letramento são as formas culturais de se utilizar o letramento, os eventos de letramento são as atividades particulares nas quais o letramento desempenha um papel (BARTON, 1994). Então, enquanto as práticas ocupam um espaço teórico de maior abstração, os eventos de letramento são mais concretos e permitem, através de exemplos particulares, generalizações acerca das práticas de letramento.

\footnotetext{
${ }^{5}$ Em Fairclough (2003), é possível encontrar modelos de análise de textos que podem servir de base para os Novos Estudos de Letramento. A ADC também estabelece diálogo com a Linguística SistêmicoFuncional (HALLIDAY; MATHIESSEN, 2004), uma vez que esta última aborda a ligação que existe entre a linguagem e a sociedade.
} 
Com base em Barton e Hamilton (2000, p. 8), práticas sociais que envolvem letramentos podem ser inferidas dos eventos, que são mediados por textos escritos, os quais, por sua vez, são o material empírico a partir do qual se desenvolvem as pesquisas sobre o letramento.

Assim, por meio de eventos de letramento - concretizados em textos escritos -, tentaremos, mais adiante, fornecer uma visão com certo nível de generalidade acerca das práticas de letramento dominantes que são reproduzidas por meio do gênero questão de prova de vestibular.

\section{ADC COMO MÉTODO}

Como dissemos, a ADC pode ser um poderoso método de análise textual para os Novos Estudos de Letramento. Contudo, é importante frisar que ela não é apenas um método, mas também uma teoria (cf. CHOULIARAKI; FAIRCLOUGH, 1999).

Tendo em vista que nosso intuito é estudar os discursos dominantes de letramento que são veiculados no gênero discursivo questão de prova de vestibular, utilizaremos a teoria/metodologia da ADC para fazer a análise dos eventos de letramento, que são concretizados em textos no formato de questão de prova.

A despeito de existirem vários tipos de questão de prova, escolhemos para análise apenas questões de prova de vestibular. Ao elegermos a ADC para analisar essas questões, nos apoiamos também na Linguística Sistêmico-Funcional (LSF), disciplina linguística utilizada pela ADC para fazer a análise textualmente orientada.

Privilegiamos neste trabalho uma abordagem de profundidade (qualitativa) em detrimento de uma abordagem quantitativa. Para desenvolver essa abordagem, selecionamos eventos representativos do nosso objeto de estudo.

Ao analisar os dados a seguir, apresentaremos a ordem do discurso em que a questão de prova de vestibular se insere. Basicamente, podemos dizer que a ordem do discurso é a faceta linguística da prática social, que, segundo Fairclough (2003), configura-se como uma articulação incessante entre discursos (formas de representar o mundo), gêneros (formas de agir linguisticamente) e estilos (tipos de identidades).

Desse modo, mostraremos como um determinado tipo de discurso (discurso dominante de letramento) é veiculado em um tipo específico de gênero discursivo (questão de prova de vestibular), que pode causar grandes impactos na identidade linguística das pessoas e na sua percepção sobre a escrita e a fala. $\mathrm{Na}$ análise, demos maior ênfase ao elemento "discurso" da ordem do discurso, mostrando os "discursos dominantes de letramento" (RIOS, 2010).

\section{AVALIAÇÃO DO LETRAMENTO}

Ao elegermos o gênero questão de prova de vestibular como objeto de estudo, não tivemos a pretensão de criticar quais são as piores ou melhores formas de avaliar as habilidades de leitura e escrita das pessoas. Nossa intenção é mostrar como esse gênero discursivo desempenha um papel de destaque na reprodução de práticas dominantes que envolvem os letramentos. 
Primeiramente, cabe notar que a avaliação para a entrada na universidade é feita por meio da escrita e sobre a escrita, isto é, nas questões de prova de vestibular não se busca avaliar o domínio que os avaliados têm dos gêneros discursivos orais. Por um lado, existe um fator operacional que motiva a utilização de um gênero discursivo escrito para a avaliação - notadamente a questão de múltipla escolha: a facilidade de se avaliar um maior número de pessoas sem a necessidade de um grande número de avaliadores. Por outro, a escrita em si é um objeto de avaliação que tem primazia sobre a fala. Em outras palavras, em uma sociedade dita letrada, é mais importante avaliar o domínio que as pessoas têm da escrita, uma vez que, numa perspectiva dominante de letramento, a escrita traz consigo um conjunto de habilidades desejáveis do avaliado.

Vejamos o evento 1 a seguir:

\section{Evento 1}

(Fuvest - SP) Entre as mensagens abaixo, a única que está de acordo com a norma escrita culta é:

a) Confira as receitas incríveis preparadas para você. Clica aqui!

b) Mostra que você tem bom coração. Contribua para a campanha do agasalho!

c) Cura-te a ti mesmo e seja feliz!

d) Não subestime o consumidor. Venda produtos de boa procedência.

e) Em caso de acidente, não siga viagem. Pede o apoio de um policial.

É interessante notar os dois classificadores que seguem a norma objeto de avaliação (veja o enunciado em itálico). Isto é, não se quer saber sobre uma norma qualquer, mas sobre uma norma que é escrita, e uma norma escrita que é culta: (((norma) escrita) culta). Numa primeira análise, parece não haver problema algum sobre o que se pede. No entanto, por uma perspectiva desnaturalizada da ideologia que envolve a escrita, cabe perguntar: 1) se uma questão de prova cobraria a regra de uma "norma oral", 2) se, ao escolher a forma escrita para avaliar, existiria a possibilidade de avaliar alguma outra norma que não seja fosse a norma culta. Para tentar responder essas perguntas, façamos a análise do participante ${ }^{6}$ principal do enunciado:

\begin{tabular}{|l|l|l|l|}
\hline A única (mensagem) & Que & está & de acordo com a norma escrita culta. (1) \\
\cline { 1 - 3 } & & & correta. (2) \\
\cline { 2 - 4 } Participante & Participante & Processo & Participante \\
\cline { 2 - 4 }
\end{tabular}

\footnotetext{
${ }^{6}$ Numa perspectiva sistêmico-funcional, as orações podem ser divididas em: a) participantes (formados por grupos nominais); b) processos (formados por grupos verbais); c) e circunstâncias (formadas por grupos adverbiais e sintagmas preposicionais).
} 
A análise acima permite visualizar que um mesmo processo permite selecionar uma variedade de participantes, como o participante (1) - usado pelo avaliador - e o participante (2). A escolha do participante (1), que constitui um atributo circunstancial ${ }^{7}$, representa uma forma de eufemizar a padronização linguística em relação ao participante (2). Essa eufemização, que constitui um modo linguístico de operação da ideologia (THOMPSON, 2002), dissimula o fato de que apenas a norma culta é considerada adequada para a escrita.

A partir da análise dos atributos, é possível concluir que não existe muita diferença entre as seguintes proposições: a) qual frase está de acordo com a norma escrita culta? b) qual frase está correta? Isso porque as únicas frases que seriam consideradas corretas nas questões de prova de vestibular são aquelas vinculadas à norma escrita culta. Prova disso é o enunciado da questão - em itálico - e o gabarito - em negrito.

Podemos apresentar outra evidência a esse respeito na questão a seguir, que também mostra a existência de uma forte vinculação da escrita aos hábitos linguísticos de grupos sociais poderosos, isto é, de grupos detentores de capital simbólico ${ }^{8}$.

\title{
Evento 2
}

\section{Enem/Vestibular/2009}

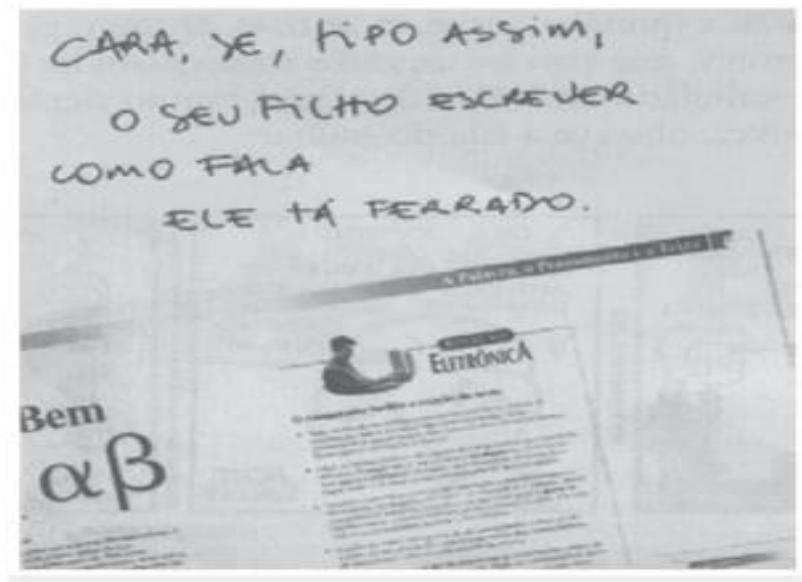

\begin{abstract}
Na parte superior do anúncio, há um comentário escrito à mão que aborda a questão das atividades linguísticas e sua relação com as modalidades oral e escrita da língua. Esse comentário deixa evidente uma posição crítica quanto a usos que se fazem da linguagem, enfatizando ser necessário
\end{abstract}

\footnotetext{
${ }^{7} \mathrm{Na}$ Gramática Tradicional, considera-se intransitivo o verbo de ligação que é seguido por um adjunto adverbial. Na gramática funcional, contudo, o adjunto adverbial é considerado um participante selecionado pelo verbo de ligação/relacional. $\mathrm{O}$ atributo, participante selecionado pelo verbo de ligação, pode aparecer em três tipos de orações relacionais: a) as intensivas; b) as possessivas; e c) as circunstanciais. Nessas últimas, o atributo ganha um sentido de tempo, lugar, modo, causa, acompanhamento, papel, ângulo e assunto.

${ }^{8}$ Tradicionalmente, o poder dos grupos sociais é atribuído ao domínio do capital econômico. Entretanto, as teorias sociais modernas, com base em Bourdieu (1983), mostram que existem outros tipos de capital: como o cultural e o social. Todas as formas de capital podem ser convertidas em capital simbólico, capaz de gerar efeitos de poder. Conforme van Dijk (2012), podemos incluir no grupo das elites simbólicas advogados, políticos, burocratas, jornalistas etc.
} 
a) implementar a fala, tendo em vista maior desenvoltura, naturalidade e segurança no uso da língua.

b) conhecer gêneros mais formais da modalidade oral para a obtenção de clareza na comunicação oral e escrita.

c) dominar as diferentes variedades do registro oral da língua portuguesa para escrever com adequação, eficiência e correção.

d) empregar vocabulário adequado e usar regras da norma padrão da língua em se tratando da modalidade escrita.

e) utilizar recursos mais expressivos e menos desgastados da variedade padrão da língua para

se expressar com alguma segurança e sucesso.

O texto-base é uma evidência de como a fala, mesmo precedendo à escrita, tem menor prestígio social nos exames e, de uma forma geral, em nossa sociedade. No textobase, representam-se as consequências da não adequação às práticas dominantes de letramento: quem não se adequar "tá ferrado". De fato, essa representação espelha a realidade discriminatória das práticas dominantes de letramento, pois, nessas práticas, selecionam-se as normas linguísticas prestigiadas, que, é claro, estão vinculadas aos grupos sociais prestigiados.

Trata-se, obviamente, de uma representação estereotipada da fala, como mostra a gíria (cara), a palavra tabu ${ }^{9}$ (ferrado) e o marcador discursivo ${ }^{10}$ (tipo assim). Essa visão estereotipada, que cria uma dicotomia entre fala e escrita, aos poucos vem sendo superada, graças, em parte, a uma vasta produção de linguistas ${ }^{11}$ sobre o tema.

O gabarito da questão - que diz ser necessário empregar vocabulário adequado e usar regras da norma padrão da língua em se tratando da modalidade escrita denota a existência de uma divisão de trabalho das variedades linguísticas (cf. FAIRCLOUGH, 1995). Isto é, enquanto o "vocabulário adequado" - leia-se a variedade dos grupos sociais poderosos - deve ser usado nos textos escritos, os textos orais são onde podem ser usados os demais vocábulos. Contudo, convém frisar que, mesmo nos textos orais, as variedades linguísticas desprestigiadas são consideradas proibidas em espaços públicos valorizados. Assim, nessa divisão de trabalho, as variedades linguísticas desprestigiadas só podem ser usadas nos espaços privados, onde não há ninguém “importante" - i.e., que possua capital simbólico (BOURDIEU, 1983).

O classificador "adequado" (vocabulário adequado) evidencia que o avaliador está alinhado àquilo que chamamos de discurso de adequação linguística (cf. FOSCACHES, 2016). Nesse discurso, a discriminação linguística ocorre de maneira velada. Em vez de usar termos explicitamente pejorativos, as pessoas que disseminam esse discurso usam termos aparentemente mais técnicos e descritivos para promover a hierarquização e discriminação linguística. Na Sociolinguística tradicional, por exemplo, é comum

\footnotetext{
${ }^{9}$ A classificação de um item lexical como tabu ou não depende muito do contexto de fala. Por exemplo, nem todas as pessoas, principalmente os mais jovens, considerariam o termo "ferrado" como um "palavrão". Possenti (2015) desenvolve uma interessante discussão sobre o tema.

${ }^{10}$ Em vez de usar o termo adjunto continuativo (HALLIDAY; MATHIESSEN, 2004), preferimos usar o termo marcador discursivo porque, além de ser autoexplicativo, acreditamos ser mais difundido que o primeiro.

${ }^{11}$ Apenas a título de exemplo, podemos citar, entre autores nacionais, Kleiman (1995), Soares (2004), Rios (2009) e Bagno (2011).
} 
encontrarmos adjetivos como "apropriado", "formal" e "adequado" sendo usados para eufemizar a imposição das variedades linguísticas de prestígio - que, por pertencerem aos grupos sociais mais poderosos, são as únicas consideradas aceitáveis para serem usadas em textos públicos e em contextos socialmente valorizados. Trata-se, pois, de um novo discurso, em que termos tradicionais como "certo" e "errado", por serem explicitamente discriminatórios, são abandonados e, em seu lugar, são usados termos aparentemente neutros, que dissimulam a discriminação linguística.

Podemos observar como esse discurso se manifesta na questão. Se o autor tivesse escolhido um classificador mais tradicional, como o classificador "correto" (vocabulário correto), criaria o sentido de que existe uma norma universalmente válida para todas as práticas que envolvem letramentos, inclusive para as práticas sociais que envolvessem a oralidade $^{12}$. Todavia, ao usar o classificador "adequado", o avaliador cria o sentido de que toda variedade linguística tem seu espaço - só não explicita, como é próprio do discurso de adequação linguística, quais variedades pertencem a quais grupos e em que espaços cada uma pode ser empregada.

Essa hierarquização das formas linguísticas pode ser encontrada em diferentes níveis de explicitude nas questões de prova. A reprodução dos discursos dominantes de letramento torna-se mais efetiva quanto menos explícito for o discurso. Afinal, a hegemonia é criada com base no consenso e, para que o poder seja exercido com efetividade, as pessoas não devem enxergá-lo (FAIRCLOUGH, 2008).

Uma das formas pelas quais essa hierarquia é depreendida é pela análise de quais temas são objeto de avaliação - isto é, quais temas são selecionados como mais importantes para serem avaliados. $\mathrm{O}$ fato de a escrita ser um objeto predominantemente de avaliação possui, então, seu significado, conforme se observa:

\section{Evento 3}

(Fuvest/ $1^{\mathrm{a}}$ Fase/Vestibular/ 2010) A única frase que segue as normas da língua escrita padrão é:

\section{a) A janela propiciava uma vista para cuja beleza muito contribuía a mata no alto do} morro.

b) Em pouco tempo e gratuitamente, prepare-se para a universidade que você se inscreveu.

c) Apesar do rigor da disciplina, militares se mobilizam no sentido de voltar a cujos postos estavam antes de se licenciarem.

d) Sem pretender passar por herói, aproveito para contar coisas as quais fui testemunha nos idos de 1968 e que hoje tanto se fala.

e) Sem muito sacrifício, adotou um modo de vida a qual o permitia fazer o regime recomendado pelo médico.

\footnotetext{
12 Esse discurso tradicional vem sendo paulatinamente enfraquecido pelo trabalho produzido por vários linguistas (cf. BORTONI-RICARDO, 2008; FARACO, 2008; ILARI; BASSO, 2009; CASTILHO, 2012; BAGNO, 2011). Contudo, é necessário frisar que, se por um lado o discurso tradicional é enfraquecido, o discurso de adequação linguística (cf. FOSCACHES, 2016) encontra respaldo no trabalho de muitos estudiosos, que, ainda que involuntariamente, ajudam a reproduzir a discriminação linguística de uma forma velada.
} 
A constante associação da escrita com a norma-padrão, a norma de prestígio, mostra o poder a ela atribuído, conforme se vê na questão acima. Como as variedades linguísticas são distribuídas de acordo com a importância dos espaços em que elas são usadas, a exigência da norma-padrão na escrita evidencia o grande valor dado à escrita. Essa importância, como estamos tentando mostrar, não advém de um valor inerente da escrita, mas sim de crenças ideológicas, sustentadas pelos discursos dominantes de letramento.

Aliás, a crença de que a escrita e a norma-padrão ${ }^{13}$ são inerentemente superiores e universalmente mais claras, descontextualizadas e acessíveis é desfeita pela própria questão acima. Compare o gabarito da questão (A janela propiciava uma vista para cuja beleza muito contribuía a mata no alto do morro) com as demais alternativas. $\mathrm{O}$ gabarito apresenta redação mais hermética que todas as outras alternativas, que, em tese, estão "erradas". Numa breve análise das alternativas "b" e "d", podemos constatar o aparecimento da relativa cortadora ${ }^{14}$, que, conforme é possível perceber da nossa vivência como falantes nativos do português brasileiro, já se incorporou à norma dita "culta" (FARACO, 2008), isto é, ao uso de pessoas com alto nível de escolarização. Esse tipo de questão mostra que o uso da norma-padrão na escrita não implica necessariamente clareza. Pelo contrário, a obediência cega às regras arcaicas da norma-padrão pode acarretar no hermetismo encontrado no gabarito da questão.

\section{Figura 1 - Cotexto do item lexical "escrita"}

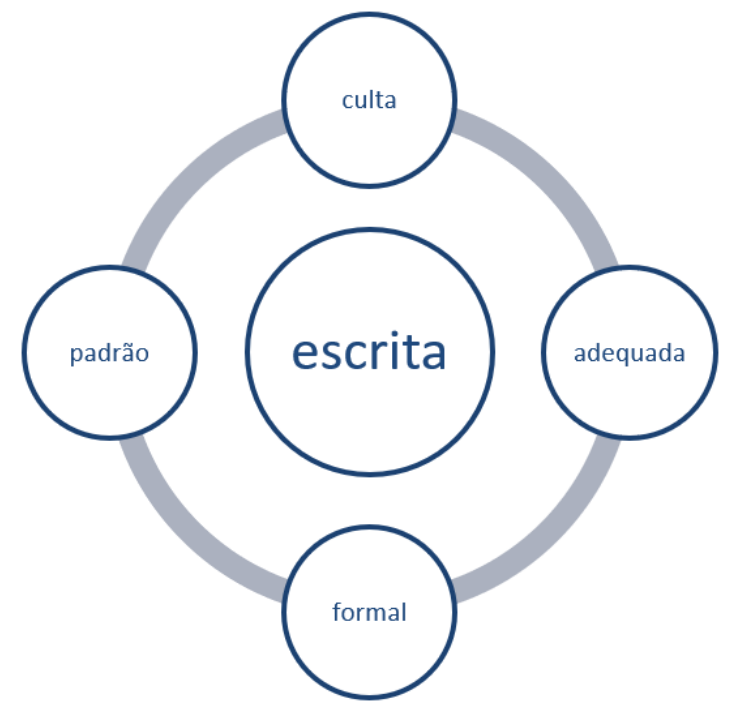

Fonte: Elaboração do autor.

\footnotetext{
${ }^{13}$ Uma interessante distinção entre norma-padrão e norma culta pode ser encontrada em Bagno (2011) e Faraco (2008). Enquanto a norma-padrão se refere a um ideal fictício de língua que não corresponde à realidade linguística empírica, a norma culta diz respeito a uma variedade linguística real: a das pessoas com alto grau de escolarização. É muito comum, inclusive entre linguistas, a confusão no uso dos dois conceitos.

14 Trata-se aqui de estratégias de relativização. Existem a relativa padrão (o menino com quem eu falei), a relativa cortadora (o menino que eu falei) e relativa copiadora (o menino que eu falei com ele). A relativa cortadora é uma construção já consolidada no português brasileiro, inclusive nos textos escritos dos falantes ditos cultos.
} 
Como vimos, o cotexto $^{15}$ que envolve a palavra "escrita" indica, através dos modificadores que acompanham a palavra, os valores que sustentam a ideologia dos discursos dominantes de letramento. De uma forma visualmente mais clara, podemos representar o cotexto que envolve o item lexical "escrita" na figura 1.

Enquanto a escrita, como se vê na figura acima, é associada ao formalismo, à norma padrão, à adequação linguística e à cultura das elites, a fala é associada ao coloquialismo, à "falta de cultura". Trata-se de uma dicotomia antiga, que, como se observa na questão a seguir, ganhou uma nova roupagem:

\section{Evento 4}

(Enem/2012) Eu gostava muito de passeá...saí com as minhas colegas...brincá na porta di casa di vôlei...andá de patins...bicicleta...quando eu levava um tombo ou outro ... eu era a :.... a palhaça da turma ... ((risos))... eu acho que foi uma das fases mais ... assim... gostosas da minha vida... essa fase de quinze... dos meus treze aos dezessete anos...

\section{A.P.S. , sexo feminino, 38 anos , nível do ensino fundamental.}

Projeto Fala Goiana, UFG, 2010 (inédito)

Um aspecto da composição estrutural que caracteriza o relato pessoal de A.P.S. como modalidade falada da língua é
a) predomínio de linguagem informal entrecortada por pausas.
b) vocabulário regional desconhecido em outras variedades do português.
c) realização do plural conforme as regras da tradição gramatical.
d) ausência de elementos promotores de coesão entre os eventos narrados.
e) presença de frases incompreensíveis a um leitor iniciante.

Primeiro, cabe notar que, conforme indica a referência, a fala transcrita é de uma mulher, de 38 anos, com ensino fundamental. A A.P.S. - sigla usada para preservar a identidade da mulher - se encaixa nos estereótipos de uma pessoa que seria rotulada como "sem cultura". A imagem da falta de cultura é reforçada pelo classificador "informal", que é usado para definir a linguagem da falante. Não que esse classificador seja pejorativo em todos os contextos. Por exemplo, um "almoço informal" provavelmente não terá um sentido negativo para a maioria das pessoas na maioria dos contextos. $\mathrm{O}$ valor das palavras depende do contexto em que são usadas. No contexto das provas - em que se avalia e hierarquiza as variedades linguísticas -, classificadores como informal tendem a ser disfóricos ao se referirem à linguagem (i.e., a possuir um valor negativo) enquanto classificadores como formal tendem a ser eufóricos (i.e., a possuir um valor positivo).

Assim, um fator essencial para depreender o sentido da palavra é o cotexto (i.e., o ambiente linguístico) em que ela aparece. O classificador informal pode ser eufórico quando estiver relacionado a palavras como "reunião informal" e "ambiente informal", mas tende a ser disfórico quando estiver relacionado à linguagem. No caso das questões de prova, estamos tentando mostrar que esse classificador está associado a uma rede de

\footnotetext{
${ }^{15}$ Grosso modo, podemos definir o termo cotexto como o ambiente linguístico em que estão inseridas as palavras.
} 
valores sobre a fala, relacionada à baixa cultura, que se opõe a uma rede de valores sobre a escrita, relacionada à alta cultura. Em outras palavras, esse classificador acaba se tornando um eufemismo para "linguagem descuidada", "linguagem inculta" etc.

Com essa análise, queremos mostrar que, apesar do léxico aparentemente descritivo, existem valores invocados (MARTIN; WHITE, 2005) sobre a fala quando examinamos sistematicamente a hierarquização linguística criada pelas questões de prova.

Voltemos agora à análise do texto-base da questão acima. O fato de a fala não estar transcrita segundo a ortografia não significa que seja "informal". Por exemplo, a queda do " $r$ " no final dos infinitivos (apócope) é um fenômeno disseminado em todas as classes de falantes do português brasileiro, inclusive os ditos cultos. As convenções ortográficas são inaplicáveis à fala, pois, como o próprio nome indica, trata-se de uma convenção sobre o que é correto (orto) em relação à escrita (grafia) - uma convenção, diga-se de passagem, muitas vezes arbitrária, como a maioria das convenções linguísticas.

Se, por um lado, as pausas são uma característica das condições de produção de textos falados, por outro lado, não necessariamente a informalidade é uma característica da fala. Essa visão decorre do discurso autônomo de letramento, que vê tanto a fala como a escrita por um prisma descontextualizado e dicotomizado .

Com relação a essa dicotomia nos estudos linguísticos, no final da década de 1970 havia uma preocupação em encontrar diferenças linguísticas e extralinguísticas entre fala e escrita, aparentemente motivada pelos estudos da grande divisão entre o mundo letrado e iletrado (STREET, 1984). Ochs (1979) e Chafe (1982) são exemplos bastante representativos de trabalhos que apontam distinções essenciais entre a escrita e a fala, salientando a existência de associações entre características linguísticas formais e variáveis relacionadas com os indivíduos - tais como idade e nível de planejamento - e variáveis relacionadas ao meio - como integração/fragmentação e distanciamento/envolvimento. Esses estudos buscavam correlacionar elementos linguísticos com essas variáveis em relação a ambos os modos de linguagem, representando-os em uma dicotomia, que tem sido estudada de forma muito limitada, focando a conversação casual na fala e o ensaio na escrita. Tendo desenvolvido seus estudos nessa direção, Tannen (1982) passou a argumentar mais tarde que esta dicotomia é enganosa e o que de fato deveria explicar tais diferenças seriam as estratégias de linguagem oral e escrita em diferentes registros e gêneros. Embora ela tivesse deslocado o foco sobre variáveis e características linguísticas, uma preocupação com a generalização sobre o que ocorre na linguagem oral e na escrita ainda permanecia. Este objetivo indicava uma insistência no mapeamento do que fundamentalmente estaria implicado nas diferenças e semelhanças entre linguagem oral e escrita.

Em contraste com esses estudos, Barton (1994) mostra como tais diferenças sustentadas por características estruturais são frágeis em uma análise mais profunda. Entre os extremos de um texto científico e uma conversa informal há uma tendência de uma estrutura para aquele gênero e de uma outra estrutura para este último, em sociedades ocidentais. Mas não se pode afirmar que existam estruturas que podem ser encontradas apenas em um gênero ou outro. Numa perspectiva semelhante, Besnier (1999) argumenta que tais estudos assumem a "linguagem escrita" como uma categoria internamente 
coerente, de modo que eles não podem alcançar êxito porque diferentes tipos, estilos ou gêneros de fala podem ser parte de diferentes tipos, estilos ou gêneros de escrita (RIOS, 2009).

É possível dizer, pois, que nem todo texto escrito é "formal" (i.e., com alto grau de monitoramento linguístico), basta observar os textos escritos nas redes sociais. Da mesma forma, nem todo texto oral é informal (i.e., com baixo grau de monitoramento linguístico), um exemplo disso são as entrevistas de emprego. De modo que a separação entre textos escritos e orais nem sempre é tão nítida quanto parece. Por exemplo, existem textos escritos que são oralizados (como os textos que ouvimos nos telejornais) e textos orais que são transpostos para escrita (como as entrevistas face a face que são transcritas para revistas). Acreditamos que existe um fator ideológico que ajuda na manutenção do prestígio da escrita: ela é mais suscetível à padronização linguística do que a fala. Talvez por isso muitos considerem a fala caótica, pois, ao analisarmos a fala, geralmente temos que levar em consideração diversas variáveis que não precisamos examinar na escrita (pausas, digressões, reações do interlocutor, impossibilidade de apagamento de constituintes gramaticais etc.). Quando se trata de linguagem, nos parece que tudo aquilo que pode ser padronizado com mais facilidade goza de mais prestígio. Isto é, tudo aquilo que pode ser colocado dentro de uma fôrma e tudo aquilo que pode ser transformado em um modelo se encaixa melhor dentro do ideal estabelecido para a linguagem.

Nessa visão, a escrita se torna um modelo linguístico tão forte que, pelas pausas e pela utilização de marcadores conversacionais, a transcrição da fala para a escrita cria a aparência de que o texto falado está errado - isso porque usamos o modelo da escrita para analisar a fala. Se reescrevêssemos segundo as convenções da escrita - sem as pausas e o marcador conversacional - o trecho do texto-base, provavelmente poucas pessoas caracterizariam o texto como informal, isto é, como um texto com linguagem inferior:

Eu gostava muito de passear, sair com as minhas colegas, brincar na porta de casa, de vôlei, andar de patins, bicicleta. Quando eu levava um tombo ou outro, eu era a palhaça da turma. Eu acho que foi uma das fases mais gostosas da minha vida: essa fase dos meus treze aos dezessete anos.

Assim, a transcrição da fala nos moldes das convenções da escrita pode mitigar a aparência de "erro" do texto falado. Não se trata, pois, de uma questão de formalidade ou informalidade, mas sim de utilizar a escrita como referência para analisar a fala e de subordinar esta àquela. A seguir mostraremos outro exemplo de como a subordinação da fala à escrita pode ocorrer:

\section{Evento 5}

(PUC-RJ) "Tem uma palavra que conheço mas que não consigo pegar." $\mathrm{O}$ trecho em destaque reproduz a fala de uma pessoa em que fica marcado o registro coloquial de linguagem. Como você poderia reescrever esse trecho usando o registro formal?

Nesta questão, apesar de abordar a linguagem falada, o avaliador a usa como exemplo a ser adequado aos moldes da escrita. Pela escolha lexical, podemos ver os valores atribuídos à fala (coloquial) e à escrita (formal). O classificador coloquial 
(sinônimo de informal) é usado como antônimo do classificador formal - este valorizado, aquele não. O léxico serve, pois, como um rótulo que os falantes usam para atribuir valor aos objetos que existem no mundo. No caso da questão, os classificadores mostram o baixo valor que a "fala" e o "registro coloquial" possuem no "mercado linguístico"16. Eis um dado linguístico que confirma essa hipótese: o avaliador demanda que o avaliado troque um produto de baixo valor (a fala no registro coloquial) por um produto de alto valor (a escrita no registro formal), que garantirá o sucesso do avaliado na questão.

É importante observar que, a partir de uma mesma proposição "Tem uma palavra que conheço mas que não consigo pegar", muitas informações podem ser solicitadas: a) qual o sentido que o verbo "ter" possui na oração? b) o verbo pegar é empregado no sentido denotativo ou conotativo? c) existem quatro verbos no período, quais se referem ao mesmo sujeito? etc. A escolha por demandar que a proposição seja reescrita para o registro formal demonstra a relação de equivalência que se faz entre fala e informalidade e entre escrita e formalidade. Afinal, não existe nenhuma informação sobre o contexto em que a fala ocorreu para classificá-la como informal. Esse tipo de classificação é feito com base unicamente em critérios ultrapassados de correção linguística, como se observa pelo uso do verbo "ter" no sentido existencial, condenado pela norma-padrão.

Apesar de a Sociolinguística não crítica postular que todas as variedades linguísticas são iguais, observamos pela análise das questões que isso não é uma verdade. Afinal, não são todas as variedades linguísticas que podem ser usadas em textos escritos valorizados - como é o caso das questões de prova de vestibular —, mas apenas as variedades linguísticas prestigiadas, isto é, as variedades linguísticas dos grupos sociais que detêm capital simbólico. Apesar de hoje termos consciência da diversidade linguística, não podemos esquecer da desigualdade entre as variedades linguísticas - que reflete a desigualdade de poder de grupos sociais em sociedades muito estratificadas. Este trabalho mostra como essa desigualdade se manifesta em eventos de letramento socialmente valorizados, especificamente nas questões de prova de vestibular.

\section{CONSIDERAÇÕES FINAIS}

Como dissemos, nosso intuito neste trabalho não foi minimizar a importância da escrita em nossa sociedade, mas tornar explícitas algumas das ideologias que a circundam. Com isso em mente, pudemos mostrar, a partir da análise das questões de prova, como o domínio da escrita ainda é associado ao domínio da norma culta, ou melhor, ao domínio da norma-padrão - que é um construto teórico de regras que não espelham a realidade do português brasileiro. Essas representações do letramento, vistas nas questões de vestibular, evidenciam a forte vinculação que ainda é feita entre a escrita e a cultura considerada de elite. Com base em Rios (2013), chamamos essas representações elitistas de letramento de "discursos dominantes de letramento".

\footnotetext{
16 A metáfora do mercado para tratar da linguagem é usada por Bourdieu (1983). Segundo o autor, a linguagem funciona dentro de um mercado, em que os bens trocados são os produtos linguísticos, e o valor desses produtos varia de acordo com a origem social da linguagem empregada.
} 
Ao analisarmos os discursos dominantes de letramento nas questões de prova de vestibular, discutimos que toda avaliação implica a seleção de determinados conhecimentos em detrimento de outros. No caso das questões de prova de vestibular, a seleção dos usos linguísticos prestigiados, sempre vinculados à escrita, mostra como a avaliação pode estar baseada nos hábitos e valores dos grupos sociais dominantes. No trabalho, pudemos ver o caráter ideológico das questões de prova não só pela eleição dos conhecimentos, mas também pela abordagem dada aos conhecimentos selecionados.

Vimos também como a fala, quando retratada, é representada como inferior à escrita e como ela (a fala) é associada aos usos linguísticos desprestigiados, o que evidencia, a despeito do vasto trabalho dentro da Linguística, que ainda há uma dicotomia entre fala e escrita. Na análise, postulamos que as variedades linguísticas são distribuídas de acordo com a importância dada aos espaços em que elas são utilizadas. Assim, consideramos que o fato de a variedade valorizada ser distribuída nos espaços em que se utiliza a linguagem escrita é um dos grandes indicativos do valor superior atribuído à escrita.

Postulamos também que os exames (concretizados no gênero questão de prova) são mais do que meios usados para medir conhecimentos, eles são verdadeiros instrumentos de controle social, capazes de definir quais são os conhecimentos válidos e quais não são dentro de uma comunidade (SHOHAMY, 2014). Com base nessa constatação, afirmamos que as questões de prova de vestibular são instrumentos fundamentais para a manutenção/transformação do status da escrita e da fala em nossa sociedade. Consequentemente, essas questões podem ser também poderosos instrumentos na relativização dos discursos dominantes de letramento (RIOS, 2013) e no combate à discriminação linguística. Assim, mesmo que o modelo autônomo de letramento seja predominante, o trabalho produzido na área de Letramento também pode ter espaço nas questões de prova de vestibular ${ }^{17}$.

Por fim, é importante frisar que, ao escolhermos analisar o aspecto linguístico das práticas sociais (ordem do discurso), quisemos mostrar como a questão de prova (gênero discursivo) pode veicular representações de letramento (discursos dominantes de letramento) que afetam a identidade linguística das pessoas (estilo). Como nosso enfoque foi o discurso dominante de letramento, nos preocupamos principalmente em mostrar como as representações ideológicas sobre o letramento dão à escrita um status superior em relação à fala e como a escrita é atrelada à alta cultura, à linguagem considerada superior e, consequentemente, ao poder. Consideramos, pois, que as representações analisadas no trabalho evidenciam como a escrita se tornou uma tecnologia alvo de disputas em nossa sociedade, dado o valor social atribuído a ela - valor reproduzido pelas questões de prova de vestibular, como mostramos.

17 Confira a edição do Enem 2015 (questão 106, caderno amarelo), que trouxe uma questão na área de linguagem com uma abordagem crítica sobre o fenômeno do letramento. 
BAGNO, M. Gramática pedagógica do português brasileiro. São Paulo: Parábola Editorial, 2011. BARTON, D. Literacy: an introduction to ecology of written language. Oxford: Blackwell Publishers, 1994.

BARTON, D.; HAMILTON, M. Literacy practices. In: BARTON, D.; HAMILTON, M.; IVANIC, R. (Eds.). Situated Literacies: Reading and Writing in Context. New York: Routledge, 2000, p. 7-15.

BESNIER, N. Orality and literacy. In: WAGNER, D.; VENEZKY, R.; STREET, B. (Eds.). Literacy: An International Handbook. Boulder \& Oxford: Westview Press, 1999. p. 127-131.

BORTONI-RICARDO, S. M. Educação em língua materna: a sociolinguística na sala de aula. São Paulo: Parábola Editorial, 2004.

BOURDIEU, P. A economia das trocas linguísticas. In: ORTIZ, R. (Org.). Bourdieu - Sociologia. São Paulo: Ática, Coleção Grandes Cientistas Sociais, v. 39, 1983, p. 156-183.

CASTILHO, A. T. de. Nova gramática do português brasileiro. São Paulo: Contexto, 2012.

CHAFE, W. Integration and involvement in speaking, writing and oral literature. In: TANNEN, D. (Ed.). Spoken and written language: Exploring orality and literacy. New Jersey: Ablex, 1982, p. 35-53.

CHOULIARAKI, L.; FAIRCLOUGH, N. Discourse in late modernity: Rethinking critical discourse analysis. Edinburgh: Edinburgh University, 1999.

DIJK, T. A. v. Discurso e poder. 2. ed. São Paulo: Contexto, 2012.

FAIRCLOUGH, N. Analysing Discourse: Textual Analysis for Social Research. London: Routledge, 2003.

Discurso e mudança social. Coordenação da tradução e revisão Izabel Magalhães. Brasília: Editora Universidade de Brasília, 2008.

FARACO, C. Norma culta brasileira: desatando alguns nós. São Paulo: Parábola Editorial, 2008.

FOSCACHES, G. V. Ideologia Linguística em questões de prova de vestibular. 151 f. Dissertação (Mestrado em Linguística) - Universidade de Brasília, Brasília, 2016.

FREIRE, P. Pedagogia do oprimido. Rio de Janeiro: Paz e Terra, 2005.

HALLIDAY, M. A. K.; MATHIESSEN, C. M.I.M. An introduction to functional grammar. 3. ed. London: Arnold, 2004.

ILARI, R.; BASSO, R. O português da gente: a língua que estudamos, a língua que falamos. 2. ed. São Paulo: Contexto, 2009.

KLEIMAN, A. Os significados do letramento. Campinas: Mercado de Letras, 1995.

LÉVI-STRAUSS, C. Tristes trópicos. São Paulo: Editora Anhembi, 1957.

MARTIN, J. R.; WHITE, P. R. R. The language of evaluation: appraisal in English. New York: Palgrave Macmillan, 2005.

NORTON, B.; KAMAL, F. The imagined communities of English language learners in a Pakistani school. Journal of Language, Identity, and Education, 2003, 301-317.

OCHS, E. Planned and unplanned discourse. In: GIVÓN, T. (Ed.). Syntax and semantics - discourse and syntax. New York: Academic Press, 1979, p. 51-80.

POSSENTI, S. Palavrões. Disponível em:

<http://www.digestivocultural.com/ensaios/ensaio.asp?codigo=337\&titulo=Palavroes $>$. Acesso em: 12 fev. 2015

RIOS, G. Literacy discourses: a sociocultural critique in Brazilian communities. Saarbrücken: Verlag Dr. Müller, 2009.

Considerações sobre letramento, escolarização e avaliação educacional. In: RESENDE, V. M.; PEREIRA, F. H. (Org.). Práticas socioculturais e discurso: Debates Transdisciplinares. Brasília: Livros LabCom, 2010, p. 77-108.

Representações de letramento em contextos locais no Distrito Federal. In: RIBAMAR JR., J.;

SATO, D. (Orgs.). Contribuições da Análise do Discurso Crítica no Brasil. Campinas: Pontes, 2013.

Culturas, discursos-de-letramento e práticas escolares. In: GUERRA, V. et al. Sociedades

contemporâneas: diversidade e transdisciplinaridade. Campinas-SP: Pontes, 2016. p. 55-85. 
SHOHAMY, E. The power of tests: A critical perspective on the uses of language tests. New York: Routledge, 2014.

SOARES, M. Avaliação educacional e clientela escolar. In: PATTO, M. H. S. (Org.). Introdução à Psicologia Escolar. 2. ed. São Paulo, 1991, p. 47-53.

Letramento: um tema em três gêneros. 2. ed. Belo Horizonte: Autêntica, 2004.

STREET, B. Literacy in theory and practice. Cambridge: Cambridge University Press, 1984.

What's "new" in new literacy studies?: critical approaches to literacy in theory and practice. 2003. Disponível em: 〈http://people.ufpr.br/ clarissa/pdfs/NewInLiteracy_Street.pdf>. Acesso em: 15 jul. 2016.

TANNEN, D. Oral and literate strategies in spoken and written narratives. Language, v. 58, n. 1, p. 1-21, 1982.

THOMPSON, J. B. Ideología y cultura moderna. Teoría crítica social en la era de la comunicación de masas. México: Universidad Autónoma Metropolitana, 2002.

\section{Recebido em: 19/04/17. Aprovado em: 28/09/17.}

Title: Dominant literacy discourses in questions of higher education admission test

Authors: Gabriel Valdez Foscaches; Guilherme Veiga Rios

Abstract: In contemporary societies, individuals are constantly evaluated by their mastery of the written language. When it comes to Higher Education admission tests, writing is the means through which one is evaluated, as well as it constitutes one of the evaluation objects. When we consider writing as an evaluation object in Higher Education admission tests, we bring to the debate the discussions developed in the New Literacy Studies and the Critical Discourse Analysis areas. Based on these two theories, we provide some answers to the following questions: a) what value is attributed to writing in the vestibular; b) what does it means to master writing; and c) are the literacy discourses adopted in the tests? We found, at the end, that the underlying literacy discourses surrounding the questions analyzed reinforce naturalized views about writing and standard language, affecting individuals' identities regarding to their use of different linguistic varieties in the written mode.

Key words: Critical Discourse Analysis. Literacy. Higher Education Admission Test.

Título: Discursos dominantes de letramiento en cuestiones de testes de admisión en la educación superior

Autores: Gabriel Valdez Foscaches; Guilherme Veiga Rios

Resumen: En las sociedades contemporáneas, los individuos son constantemente evaluados por el dominio que poseen de la escrita. En el caso de las pruebas de admisión en cursos superiores, la escrita es simultáneamente medio y objeto de evaluación. Cuando consideramos la escrita cómo objeto de evaluación en pruebas de admisión, traemos para el debate las discusiones desarrolladas en el área de los Nuevos Estudios de Letramiento y del Análisis del Discurso Crítica. Basado en estas dos teorías, suministramos algunas respuestas para las siguientes cuestiones: a) ¿qué valor es atribuido a la escrita en pruebas de admisión de cursos superiores; b) qué se comprende por dominio de la escrita; y c) cuáles son los discursos de letramiento adoptados en las pruebas? Encontramos, al fin, que los discursos de letramiento subyacentes a las cuestiones analizadas refuerzan visiones naturalizadas sobre la escrita y la norma-estándar, afectando las identidades de los individuos en relación al uso que hacen de variedades lingüísticas en esa modalidad.

Palabras-clave: Análisis del Discurso Crítico. Letramiento. Pruebas de admisión en la Educación Superior.

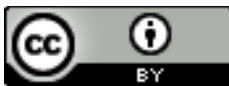

Este texto está licenciado com uma Licença Creative Commons Atribuição 4.0 Internacional. 